\title{
Basic Self-Esteem: Dynamics and Inertia in the Process of Social Interaction
}

\author{
Anna Kuzmina ${ }^{1}$, Olga Lyubimova ${ }^{1, a *}$, Beybitgul Turganbaeva ${ }^{2}$, \\ Tatyana Volkova ${ }^{1}$ \\ 1 Altai State University, Faculty of Psychology and Pedagogy, 656049, 61 Lenin prospekt, \\ Barnaul, Russia \\ 2 Shakarim State University of Semey, 071412, 20a Glinka str., Semey, Kazakhstan \\ alubimovaom@gmail.com \\ ${ }^{*}$ Corresponding author
}

Keywords: basic self-esteem, self-relation, heuristic model, education

\begin{abstract}
The paper reviews the factors determining the dynamic and inert components of basic self-esteem, including the heuristic model of basic self-esteem proposed by S. R. Pantileev. The authors notice the importance of interpreting results of modern socio-psychological empirical research, especially when such a research is used in education.
\end{abstract}

In our opinion, the term "basic self-esteem" is a meaningfully close equivalent of the term "self-relation", which has adopted in Russian psychology and is quite popular in the research community. In its content, it is close to the Jungian understanding of the self [1], the emotional value of self-experience by the subject. Analysis of the literature showed that a number of authors (R. Burns, C. Cooley, J. Mead) interpreted the concept of self-relation as close to the concept of "I-concept". And in this regard, they pointed out the importance of getting ratings from the people around them when forming a self-attitude. According to the authors, the specificity of the society in which a person is located plays a decisive role in the process of formation of a person's self-image. According to the works of C. Cooley, that social conditions determine one's personality. At the same time, a person's ideas about how he is appreciated by those around him determine his I-concept. Thus, the author developed the theory of the "mirror I," which reflects the idea that, due to external evaluations, a person develops ideas about himself, his features and shortcomings, which closely interact with self-relation. A similar point of view on the emergence of self-relation was reflected in the works of R. Burns. He believed that the self-concept is formed due to the influence of various incentives from outside that are experienced and experienced by a person during his life. A person, according to R. Burns, is a complex system, which has the main task - the implementation of high-quality and harmonious interaction with the environment, where the I-concept is the main factor that contributes to this consistency, since in most cases, the I-concept is directly involved in determining human activities [2-4].

The need for a more careful study of the emotional-axiological attitude towards oneself, its transformation into a subject of psychological analysis and terminological design arises as a result of the paradoxical self-observations of customers, whose basic self-esteem is opposite to the social success of a person.

How is the identity of experience (I, the self) belonging to the same person created from the variety of experiences? Another question is why this identity is experienced on the emotional level in one case - as a spectrum of negative emotions and feelings despite external successes, and in the other case it turns out to be uncritically positive despite the presence of negative feedback from the social environment? What is the empirically identifiable psychological fabric of the self? Does basic self-assessment have an internal system organization? Which of its elements are stable, and which dynamic changes are in the process of social interaction?

The internal heterogeneity of basic self-esteem was reviewed in their works of S. Coopersmith, M. 
Rosenberg, L. Wells, J. Marvel, and C. Rogers. In the opinion of S. R. Pantileev, global self-esteem does not simply reflect a certain generalized feeling "for" or "against" an individual's own "I". She herself has a complex structure, which is determined by various factors and processes. Consistently developing the views of A. N. Leontyev, V. V. Stolin describes the semantic nature of the psychological reality of S. R. Pantileev as a mechanism that forms global self-esteem, which represents dynamic experience and the formation of the meaning of "I" (self) in various types of social interaction.

The logical following of the category "meaning," the distribution of models of the mechanisms of generation of semantic formations forms an idea of the internally heterogeneous structure of the basic selfesteem (self-relation). Being born in the sphere of the unconscious, as a result of the verbalization of meaning, it acquires the forms of self-presentations and self-descriptions that are familiar to the researcher, such as "I-image" and "I-concept." With this approach, the emotional-axiological dimension and the verbalcognitive component of self-relation are the different forms of manifestation of one process: the formation of the meaning of the self (Table 1).

TABLE 1. THE MECHANISM OF THE FORMATION OF BASIC SELF-ESTEEM ACCORDING TO S.R. PANTILEEV.

\begin{tabular}{|c|c|c|}
\hline \multicolumn{2}{|c|}{ PROCESSES OF FORMATTING THE MEANING OF “I” IN CONSCIOUSNESS } & \multirow{4}{*}{$\begin{array}{l}\text { Implementation of } \\
\text { behavioral models of } \\
\text { the inter- and intra- } \\
\text { psychic plan in order } \\
\text { to achieve the } \\
\text { maximum possible } \\
\text { satisfaction of actual } \\
\text { needs. }\end{array}$} \\
\hline $\begin{array}{l}\text { Symbolic representation } \\
\text { of the "meaning of I" to } \\
\text { the consciousness of the } \\
\text { subject. }\end{array}$ & $\begin{array}{l}\text { Emotional value reactions to the "meaning of I", } \\
\text { - Labeling positive/negative experience of } \\
\text { meeting the needs, } \\
\text { - Stimulating the launch of emotionally- } \\
\text { supported behavior aimed at transforming the } \\
\text { conditions for satisfying the needs. }\end{array}$ & \\
\hline \multicolumn{2}{|c|}{$\begin{array}{l}\text { SPACE OF TRANSITION OF UNCONSCIOUS PSYCHOLOGICAL CONTENT IN } \\
\text { RECOGNIZABLE }\end{array}$} & \\
\hline $\begin{array}{l}\text { A dynamically and } \\
\text { hierarchically organized } \\
\text { system of personal } \\
\text { motivation, consistently } \\
\text { developing in } \\
\text { ontogenesis, from basic } \\
\text { needs to the level of } \\
\text { values. }\end{array}$ & $\begin{array}{l}\text { The subject's presentation about conditions in } \\
\text { which the needs-based activities take place: } \\
\text { mental representations of the surrounding space } \\
\text { and ideas and their own qualities that contribute } \\
\text { to or hinder the satisfaction of needs }\end{array}$ & \\
\hline \multicolumn{2}{|c|}{ PROCESSES OF THE BIRTH OF THE MEANING OF “I” } & \\
\hline
\end{tabular}

S. R. Pantileev proposes the principle of a hierarchically-dynamic organization in the structure of selfrelation, based on the principles developed by A. N. Leontiev's ideas about the hierarchically dynamic structure of the motivational sphere of a person, determined by semantic motives. Currently, the Russian test base presents two questionnaires illustrating ideas about the internal structure of the basic selfassessment. The test questionnaire of self-relation was developed by V. V. Stolin and S. R. Panteleev. This 1985 version of the questionnaire allows us to identify three levels of self-relation, differing in the degree of generalization: (i) global self-relation; (ii) self-relation, differentiated by self-esteem, autympathy, selfinterest, and expectations of self-relations; (iii) the level of specific actions (readiness for them) in relation to your "I" [5-6]. The multidimensional questionnaire for the study of self-relation (a method for the study of self-relation), being created by S. R. Pantileev in 1989, contains 110 statements distributed on 9 scales. The purpose of the test is to study the emotional value component of self-awareness. Scales: openness, selfconfidence, self-leadership, mirror-I, self-worth, self-acceptance, self-attachment, self-conflict, selfincrimination. These scales were derived from factorization and meaningful interpretation of empirical data. Thus, the question of the component structure of self-relation and its true conceptual and methodological substantiation remains open.

The heuristic nature of the model lies in the fact that self-relation does not close in the inner space of the self-consciousness of an individual, but through motives it is associated with the vital activity of the subject. Social environment sets the self-description thesaurus and its semantic interpretation (self-esteem of 
a mature man and a teenager does not coincide in meaning).

This brings us to another important characteristic of basic self-esteem: its components are not additive. The leading role of an element is determined, on the one hand, by the relationship with the actualized components of the motivation-need sphere, and on the other hand, it is determined by the current conditions. The relationship with the social context is achieved not only through feedback and reflection mechanisms, which can be unproductive due to the activation of psychological defenses [7-8]. So, S. R. Pantileev identified two styles of self-relation [5]. One of them was called "Protection of self-relation with the help of I-falsification." The effectiveness of protection by falsifying the "I", in terms of avoiding a direct negative attitude towards oneself (that is, disliking oneself, disrespect for oneself), is not successful in protecting oneself from the negative attitude of others. The subject projects an unconscious negative (not allowed into the consciousness using this type of protection) self-relation in the form of waiting for a negative assessment of others. Another style of self-defense was called "aggressive protection". The points included in the corresponding factor indicate an explosive, urgent mobilization of protection against the threat of "I": aggression against the critic or the offender (without later discrediting him), subsequent honest recognition of his hot temper and irritability.

The hierarchical principle of the organization of the motivational sphere of the personality forms the system of stable and variable components of the global self-assessment [9], determines the dependence of the degree of positive self-attitude on the satisfaction of the significant values for the subject [10].

At the moment, the concept of the self-relation of S. R. Pantileev is the most developed and empirically based in the Russian psychological community (A. V. Vizgina, E. T. Sokolova, R. B. Sapozhnikova, etc.). E.T. Sokolova conducted an extensive analysis of the effect of maternal self-relation on the formation of the child's self-relation, and also investigated self-attitude as the leading etiological factor in the formation of borderline personality disorders.

An experimental study showed that motivational conflicts and the low differentiation of cognitive and affective "forming" self-awareness are the main sources of instability of self-relation with neurosis. The instability of the system of self-assessments is based on two independent factors: (i) the existence of a conflict between the leading motives affecting the change in the hierarchy of scales of preference and stability of ideals; (ii) cognitive non-differentiability, affecting changes in the hierarchy of scales and ideas about oneself and manifested: a) in a small number of semantic constructs; b) in their cohesion, "monolithicity", when minor changes in one semantic construct lead to a change in many other semantic constructs, which causes uncontrollable fluctuations of ideas about themselves and hierarchy of value scales. The phenomenon of instability of self-relation (identified E. T. Sokolova) has only a very superficial resemblance to the fluctuations of the system of private self-assessments. "The essence of the revealed phenomenon requires recognition that there is an unusually non-viable, specific structure of "I" that does not tolerate changes and impacts, since any, even the smallest, change of I-experience causes inappropriate individual changes, transforming an I-concept into its complete collapse $\langle\ldots>$. The integration of negative and positive "I" images into a holistic and consistent I-concept is difficult. Opposite I-images are updated alternately, and with them changes its sign to the opposite emotional-axiological attitude towards "I" [8].

Thus, the basic self-esteem acts as a system of personal education, which has dynamic and inert components determined by the characteristics of the social context and the internal space of an individual.

\section{References}

[1] Jung, C. G. (1958). The undiscovered self. New York, N.Y.

[2] Burns, R. (1986). Developing self-concept and education. Moscow, Russia: Progress.

[3] Cooley, C. (1930). Sociological theory and social research. Moscow, Russia.

[4] Mead, J. G. (2009). Selected works: collection of translations. Moscow, Russia: INION RAS.

[5] Pantileev, S. R. (1991). Self-relation as an emotional-evaluation system. Moscow, Russia: Moscow University Press. 
[6] Glukhanyuk, N. S. (2005). Psychodiagnostic workshops: study guide. Moscow, Russia: Publishing House of the Russian Academy of Education (RAO).

[7] Lyubimova, O. M. (2003). Self-teacher as an indicator of satisfaction of personally significant values. Education and Social Development of the Region, 3(4), pp. 109-113.

[8] Sokolova, E. T. (1989). Self-consciousness and self-esteem with personality anomalies (p. 339). Moscow, Russia: MSU.

[9] Kuzmina, A. S. (2018). Invariant and variable parameters in the structure of students' self-attitudes. Psychologist, 1, pp. 57-65.

[10] Lyubimova, O. M. (2012). Protective-coping behavior of students in the system of maintaining a positive selfattitude. Psychology of Education, 7, pp. 35-44. 